Full length article

\title{
The influence of hyperglycemia on the remodeling of urethral connective tissue in pregnant rats
}

\author{
Gabriela Marini $^{\mathrm{a}, \mathrm{b}, *}$, Fernanda Piculo ${ }^{\mathrm{b}}$, Giovana Vesentini ${ }^{\mathrm{b}}$, Débora C. Damasceno ${ }^{\mathrm{b}}$, \\ Flávia K. Delellac, Iracema M.P. Calderon ${ }^{\mathrm{b}}$, Firouz Daneshgari ${ }^{\mathrm{d}}$, Sérgio L. Felisbino ${ }^{\mathrm{c}}$, \\ Angélica M.P. Barbosa ${ }^{\mathrm{b}}$, Marilza V.C. Rudge ${ }^{\mathrm{b}}$ \\ a Universidade do Sagrado Coração (USC), Bauru, São Paulo, Brazil \\ ${ }^{\mathrm{b}}$ UNESP - Univ Estadual Paulista, Botucatu Medical School, Department of Gynecology and Obstetrics, Laboratory of Experimental Research on Gynecology \\ and Obstetrics, Botucatu, São Paulo, Brazil \\ ${ }^{\mathrm{c}}$ UNESP - Univ Estadual Paulista, Institute of Biosciences, Department of Morphology, Botucatu, São Paulo, Brazil \\ ' Case Western Reserve University, Department of Urology, Cleveland, OH, USA
}

\section{A R T I C L E I N F O}

\section{Article history:}

Received 19 June 2017

Received in revised form 14 December 2017

Accepted 15 December 2017

\section{Keywords:}

Collagen

Diabetes

Extracellular matrix

Pregnancy

Rats

Urethra

\begin{abstract}
A B S T R A C T
Objective: To analyze the distribution and quantification of the key structural extracellular matrix components of the urethral tissue in a rat model of hyperglycemia and pregnancy.

Study design: A total of 120 female Wistar rats were distributed into the following four experimental groups: virgin, pregnant, hyperglycemic and hyperglycemic + pregnant groups. The urethra was harvested for histochemical, morphometric, immunohistochemical, Western blot and glycosaminoglycan analyses. All protocols were approved by the Institutional Animal Care and Use Committee of Botucatu Medical School (process number 828-2010).

Results: The hyperglycemic + pregnant group showed significantly increased stiffness in urethral tissue. The total striated muscle was decreased, with increased deposition of collagen fibers around the muscle fibers and a change in the organization of the collagen fibrils. An increase in the relative collagen type I/III ratio and a decrease in total glycosaminoglycans were also observed.

Conclusions: This study provides the first line of experimental evidence supporting a metabolic relationship between hyperglycemia and urethral remodeling of connective tissue in pregnant rats. The different organization of the collagen fibrils and the profile of glycosaminoglycans found in urethral samples suggest that the pathology of the urethral fibromuscular system could be related to hyperglycemia-induced pelvic floor dysfunction in women, which has direct clinical implications with the possibility to develop new multidisciplinary treatments for improving the health care of these women.
\end{abstract}

(C) 2017 Elsevier B.V. All rights reserved.

\section{Introduction}

Pelvic floor disorder (PDF) and diabetes mellitus (DM) are two prominent conditions that affect thousands of people worldwide. DM is reaching epidemic proportions worldwide, with estimates that the prevalence will reach 592 million cases in 2035 [1]. Furthermore, the weighted prevalence rate of one or more PFDs was $25.0 \%$ of adult women in the U.S., including $17.1 \%$ of women with moderate-to-severe urinary incontinence(UI), 9.4\% with fecal

\footnotetext{
* Corresponding author at: Universidade do Sagrado Coração Pró Reitoria de Pesquisa e Pós Graduação, R. Irmã Arminda, 10-50 - Jardim Brasil, CEP 17011-160, Bauru, São Paulo, Brazil.

E-mail address: gabriela.marini@usc.br (G. Marini).
}

incontinence, and 2.9\% with prolapse [2]. Moreover, the association between DM and PFD has been recently described in epidemiologic studies [3] and reviews [4], and it has been shown that urinary tract symptoms are present in 75\% of DM patients [5] and that worsening glycemic control is associated with an increased risk for stress incontinence [6] and pelvic organ prolapse [7] in women.

However, the impact of DM during pregnancy on postpartum PFD has not been widely investigated. Researchers of two different countries independently but simultaneously reported that gestational DM confers long-term postpartum genitourinary dysfunction that persists for two years after delivery [8,9]. This is a surprising outcome because it contradicts traditional knowledge that the effects of DM disappear soon after childbirth. 
Several clinical studies have provided evidence that pelvic floor skeletal muscles $[10,11]$ and extracellular matrix (ECM) components such as collagen [12] and glycosaminoglycans (GAGs) [13] contribute to female pelvic floor function, and research with animals, according to the "bedside to bench" principle of translational research, have been revealed that both muscle and the ECM play important roles in muscle dysfunction, motivating further research regarding what alterations occur in the urethral ECM of diabetic pregnant rats.

The ECM plays a key role in muscle fiber force transmission, maintenance, and repair. It is considered an important factor for genitourinary tract supportive structures [14]. Alterations in ECM components have been reported in women with PFD [15,16], and decreased synthesis of ECM components or increased proteolysis in the urethra were observed in mice undergoing vaginal distension [17].

Some studies have examined the relationship between ECM components (particularly collagens) and diabetes [18], PFDs [19] and pregnancy [20], although few comparative data are available.

Given the importance of the ECM in maintaining healthy skeletal muscle and the necessity to use a biochemical approach to consistently explore the alterations induced by hyperglycemia and pregnancy in urethral tissue, the aim of this study was to analyze the distribution and quantification of the key structural ECM components, such as type I and III collagens, the collagen type I/III ratio and GAGs, in the urethras of streptozotocin (STZ)-induced hyperglycemia in pregnant rats.

The localization and expression of collagen types and GAGs have not yet been examined in urethral tissue. Therefore, we hypothesized that the proposed analyses would reveal another facet of tissue damage caused by hyperglycemia in pregnancy and provide a translational research strategy to better understand the mechanisms related to PFD incidence in diabetic women. These findings also point to new therapeutic approaches for the treatment of PFD.

\section{Materials and methods}

\section{Experimental animals and design}

All protocols were approved by the Institutional Animal Care and Use Committee of Botucatu Medical School (process number 828-2010). The animals were maintained under controlled temperature conditions $\left(22-25^{\circ} \mathrm{C}\right)$, relative humidity $(55 \%)$, and a $12 \mathrm{~h}$ photoperiod (light period beginning at 7 a.m.). The animals had free access to water and chow. The female rats were randomly allocated into the following four groups: a virgin group $(\mathrm{N}=30)$, a pregnant group $(\mathrm{N}=30)$, a hyperglycemic group $(\mathrm{N}=30)$ and a hyperglycemic + pregnant group $(\mathrm{N}=30)$. Hyperglycemia was induced at 90 days of age through one STZ (Sigma Chemical Company, St. Louis, MO, USA) injection. STZ was administered intravenously at $40 \mathrm{mg} / \mathrm{kg}$ to produce a permanent and severe hyperglycemic state. Blood samples were taken $72 \mathrm{~h}$ after the STZ injection to confirm hyperglycemia (i.e., a blood glucose level $>300 \mathrm{mg} / \mathrm{dL}$ ). Blood glucose concentrations were measured with a One-Touch Ultra glucometer (LifeScan, Johnson and Johnson ${ }^{\circledR}$, Milpitas, CA, USA), and the values were expressed in $\mathrm{mg} / \mathrm{dL}$. Hemoglobin A1c (HbA1c) levels $(\mathrm{n}=10 /$ group) were determined using a turbidimetric commercial assay Kit (HBA1C Turbiquest, Labtest, MG, Brazil). The Kit utilizes latex immunoassay agglutination to measure the HbA1c level in whole blood hemolyzed.

In the hyperglycemic + pregnant group, mating activities were initiated 7 days after hyperglycemia induction. The female rats were mated overnight with non-hyperglycemic male rats. The morning when sperm was found in the vaginal smear was designated gestational day 0 . Glycemic levels were assessed three times during pregnancy (7th, 14th and 21th days).

All groups of the female rats were killed on day 21 of pregnancy via $80 \mathrm{mg} / \mathrm{kg}$ i.p. Thiopentax $\AA$ injection. The offspring were removed, weighed and lethally anesthetized with sodium thiopental (3\% Thiopentax ${ }^{\circledR}$ ), and the maternal urethrovaginal tissues were harvested (a cross-section of the mid-urethra and anterior vagina). The anterior vagina just was removed to better preserve the urethral tissue. The investigators controlled the longitudinal axis (proximal to distal) of the urethra by marking with a permanent ink pen to identify the distal urethra. All analyses were performed at the same points along the urethral longitudinal axis: the mid-urethra region, where the striated muscle layer becomes denser [21].

\section{Histological examination, immunohistochemical stain, and morphometric analysis}

A portion of the samples ( $\mathrm{N}=10$ samples/group) was immersed for a period of $4 \mathrm{~h}$ in neutral buffered formalin containing $4 \%$ formaldehyde and then embedded in paraffin. Then, $4-\mu m$-thick sections were cut in the mid-urethra using a rotor microtome. The sections were stained with Masson's trichrome (used for distinguishing collagen fibers from muscle tissue) and picrosirius red (to enhance the birefringence of collagen fibers observed under polarized light) for histological examination and morphological analyses. Cross-sections of the specimens were examined under normal and polarized light, and the images were digitalized using a Leica DMLB 80 microscope connected to a Leica DC300FX camera and digitalized. Morphometric analysis was performed by interactive measures under $\times 20$ magnification in four different fields, from 10 different individual urethral sections for each experimental group. Morphometric analysis was performed with Image-Pro Plus 7.0 image analysis software (Media Cybernetics, Ins. USA) at Case Western Reserve University (Ohio, USA). Interactive measurements were used to delimit the striated and smooth muscle areas, and automatic detection of red and blue colors in the Masson's trichrome-stained sections were used to determine the area in $\mathrm{mm}^{2}$ of muscle and connective tissue. With the mean area of each urethral striated muscle, smooth muscle and connective tissue, we determined the ratio among these components.

For immunohistochemistry ( $\mathrm{N}=10$ samples/group), the samples were frozen in liquid nitrogen and kept at $-80^{\circ} \mathrm{C}$ for cryostat sectioning ( $6 \mu \mathrm{m}$ thick). Sections were incubated with antibodies directed towards type I collagen (1:500; ab90395; bccam $^{\mathrm{TM}}$ ) and type III collagen (1:500; ab6310; Abcam $\left.^{\mathrm{TM}}\right)$. The primary antibody was detected using a secondary peroxidase-conjugated antibody (Santa Cruz Biotechnology, Santa Cruz, CA, USA). Chromogen color development was accomplished with 3,3'-diaminobenzidine tetrahydrochloride (Sigma, St. Louis, MO, USA). Slides were counterstained with Harris's hematoxylin.

\section{Protein extraction and Western blot analysis for collagen I and collagen III}

The frozen urethra samples ( $\mathrm{N}=5$ samples/group) for protein extraction and collagen I and collagen III Western blot analysis were mechanically homogenized in $50 \mathrm{mM}$ Tris- $\mathrm{HCl}$ buffer $\mathrm{pH} 7.5$, $0.25 \%$ Triton X-100 and EDTA using a Polytron homogenizer (Kinematica, Lucerne, Switzerland) for $30 \mathrm{~s}$ at $4{ }^{\circ} \mathrm{C}$. Following centrifugation of the homogenate, the protein was extracted from the supernatant and then quantified, as described by Bradford (1976). Equal amounts of protein $(70 \mu \mathrm{g})$ from the frozen urethra samples were heated at $95^{\circ} \mathrm{C}$ for $5 \mathrm{~min}$ in the sample-loading buffer and then subjected to SDS-PAGE under reducing conditions 
and transferred to nitrocellulose membranes (Sigma Chemical Co. St. Louis, MO).

The blots were blocked with $3 \%$ bovine serum albumin in TBST (10 mM Tris- $\mathrm{HCl} \mathrm{pH} \mathrm{7.5,} 150 \mathrm{mM} \mathrm{NaCl}$, and $0.1 \%$ Tween-20) for $1 \mathrm{~h}$ and probed overnight with the primary antibody, anti-type I collagen (1:500; ab90395; Abcam ${ }^{\mathrm{TM}}$ ) and anti-type III collagen
(1:200; ab6310; Abcam $\left.^{\mathrm{TM}}\right)$. Goat anti- $\beta$-actin antibody $(1: 1000$; Santa Cruz Biotechnology, Santa Cruz, CA, USA) served as the loading control. After incubation with the corresponding horseradish peroxidase-conjugated secondary antibodies, the blots were detected through chemiluminescence (Immun-Star ${ }^{\mathrm{TM}} \mathrm{HRP}$ Chemiluminescent Kit, BIO-RAD). Protein expression levels were
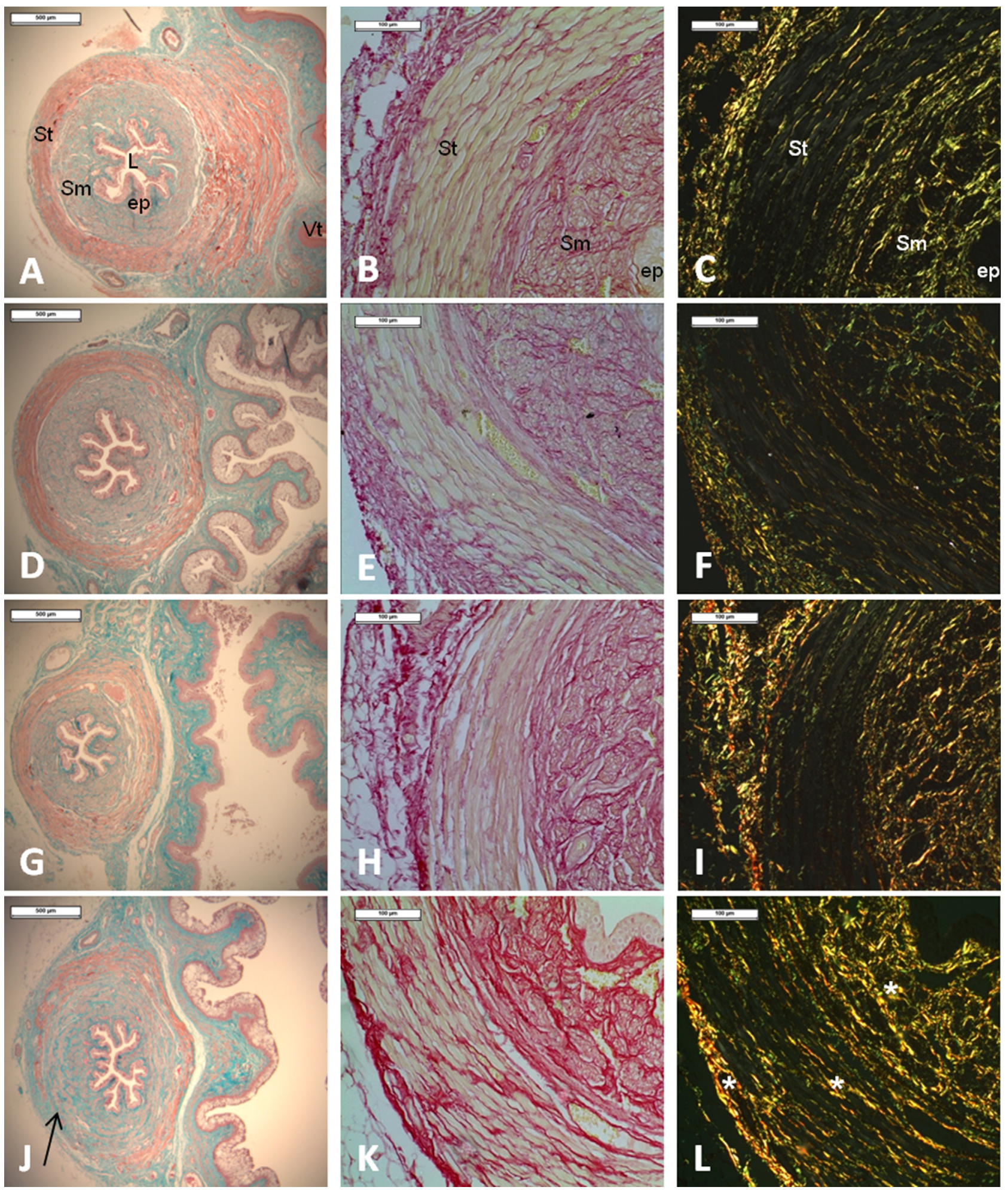

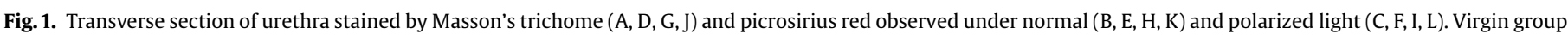

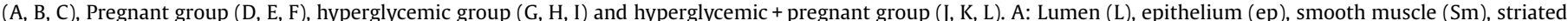

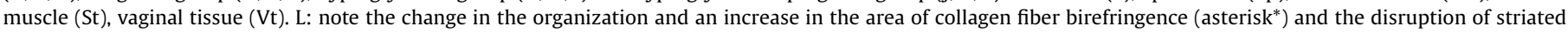
muscle fibers (arrow $\uparrow$ ) in the pregnancy + hyperglycemic group. Scale bars: A, D, G, J=500 $\mu \mathrm{m} ; \mathrm{B}, \mathrm{C}, \mathrm{E}, \mathrm{F}, \mathrm{H}, \mathrm{I}, \mathrm{K}, \mathrm{L}=100 \mu \mathrm{m}$. 
obtained by analyzing the densitometry of the bands and expressed as integrated optical density (IOD). The expression levels of type I and type III collagens were normalized to the $\beta$-actin values. The analysis was performed with Image $1.48 \mathrm{a}$ software (Wayne Hasband, National Institute of Health). Normalized data are expressed as the means \pm SD.

\section{Quantification and characterization of sulfated glycosaminoglycans}

After washing in phosphate-buffered saline (PBS, $5 \mathrm{mM}$ phosphate buffer, $0.15 \mathrm{M} \mathrm{NaCl}$ and $50 \mathrm{mM}$ EDTA), total urethra $(\mathrm{n}=5)$ were immersed into acetone for $12 \mathrm{~h}$ and dried in a histological oven $\left(37^{\circ} \mathrm{C}\right)$ for $12 \mathrm{~h}$. GAGs were extracted with papain solution ( $40 \mathrm{mg} / \mathrm{g}$ tissue) in $100 \mathrm{mM}$ sodium phosphate buffer $(\mathrm{pH}$ 6.5 ) containing $40 \mathrm{mM}$ EDTA and $80 \mathrm{mM} \beta$-mercaptoethanol for $24 \mathrm{~h}$ at $50^{\circ} \mathrm{C}$. After precipitation using $90 \%$ trichloroacetic acid (TCA) for $10 \mathrm{~min}$ at $5{ }^{\circ} \mathrm{C}$, the samples were centrifuged and submitted for precipitation with methanol for $12 \mathrm{~h}$ at $5^{\circ} \mathrm{C}$. The precipitate was resuspended in water and used to measure the total sulfated GAGs. Before electrophoresis, $5 \mu \mathrm{g}$ of each sample was treated with DNAse $(10 \mathrm{mg} / \mathrm{mL})$ in $20 \mathrm{mM}$ Tris- $\mathrm{HCl}$ buffer, $\mathrm{pH}$ 7.4 for $30 \mathrm{~min}$ at $37^{\circ} \mathrm{C}$. Then, the GAGs, chondroitin sulfate (CS), dermatan sulfate (DS) and heparan sulfate (HS) were separated by electrophoresis in agarose gel $(0.5 \%)$ in $0.05 \mathrm{M}$ propylene diamine at $0.1 \mathrm{~mA}$ for $45 \mathrm{~min}$. The agarose gels were fixed in Cetavlon and stained with $0.2 \%$ TB. The gels were washed with a solution containing $50 \%$ ethanol and $1 \%$ acetic acid to observe the bands. The identification of GAGs was confirmed by digestion with chondroitinases $B$ and AC. With the exception of CS, the bands of DS and HS GAGs were identified and quantified using the Image $\mathrm{J}^{\mathrm{TM}}$ software for each sample (as quintuplicates). The IOD was obtained, and the analysis was performed with Image 1.48 software (Wayne Hasband, National Institute of Health). Data were expressed as the means \pm SD.

\section{Statistical analysis}

Results are expressed as the means \pm SD. Comparisons of the measurements of the virgin, pregnant, hyperglicemic and hyperglicemic+ pregnant groups were performed individually using ANOVA. Dunnett's test was used to compare the "hyperglycemic + pregnant" study group with the other three control groups (virgin, pregnant and hyperglycemic), and $\mathrm{P}<0.05$ was considered to be significant. All analyses were performed using SAS software for Windows, v.9.2.

\section{Results}

On day 21 of the experiment, the hyperglycemic and hyperglycemic + pregnant groups presented glycemic levels of $584.8 \pm 33.9$ and $497.0 \pm 60.4 \mathrm{mg} / \mathrm{dL}$, respectively, and the virgin and pregnant groups presented glycemic levels of $81.6 \pm 5.0$ and $82.6 \pm 7.7 \mathrm{mg} / \mathrm{dL}$, respectively. HbA1c levels were significantly greater in the hyperglycemic groups (13.45\%) than in the normoglycemic groups $(3.8 \%)(\mathrm{p}<0.05)$.

Histological analysis of urethral connective tissue by Masson's trichrome and picrosirius red staining observed under polarized light revealed mild focal disruption of the striated muscle fibers with increased deposition of collagen fibers around the striated muscle in the hyperglycemic + pregnant group, characterizing a change in the organization of the collagen fibrils due to higher cross-linking (Fig. 1).

Morphometric analysis revealed no between-group differences in the urethral connective tissue area/total area ratio and in the urethral connective tissue in smooth area/smooth muscle area. However, the ratios of the urethral connective tissues in the striated area/striated muscle area and the urethral connective tissue in the striated area/urethral connective tissue in smooth muscle area were significantly greater in the hyperglycemic + pregnant group than in the pregnant group. All ratios of these morphologic variables are listed in Table 1.

Immunohistochemistry results showed that type I and III collagens were homogeneously distributed in the extracellular matrix in the four groups (Fig. 2). Western blot analysis showed no significant differences between groups in terms of the type I collagen and type III collagen expression levels (Fig. 2). However, the collagen type I/III ratio in the urethra was higher in the hyperglycemic + pregnant group than in the virgin group (Fig. 3).

The results of total sulfated GAG quantification analysis $(\mathrm{mg} / \mathrm{g}$ tissue) are shown in Fig. 4. GAG content was significantly reduced in the hyperglycemic + pregnant group. Further analysis of GAG content through densitometry showed that the amount of DS was predominant in all groups without any significant differences. HS was significantly lower in the hyperglycemic group than in the virgin group. Two GAGs, CS and keratin sulfate (KS), were not identified in the gel due to their low amounts in the tissue.

\section{Discussion}

The present study showed that in pregnant rats with hyperglycemia, the two major components of urethral tissue (connective tissue and striated muscle) are altered. The total striated muscle was decreased and involved with more connective tissue as revealed by a change in the organization of the collagen fibrils, an increase in the relative collagen type I/III ratio, and a decrease in total GAGs levels. These findings suggest that pathology of the urethral fibromuscular system could be related to hyperglycemia-induced pelvic floor dysfunction in women, which has direct clinical implications with new possibilities for studying multidisciplinary treatments to improve the health care of these women.

Female PFD is a common disorder that disables many women with diabetes during pregnancy but its etiology remains unclear [[22-24],9]. Previous translational studies confirmed that a reduction in muscle content by diabetes may negatively affect the structural and functional integrity of the urethra [22-24].

Table 1

Morphometric analysis of urethral tissue in the four studied groups.

\begin{tabular}{|c|c|c|c|c|}
\hline & VIRGIN & PREGNANT & HYPERGLYCEMIC & HYPERGLYCEMIC + PREGNANT \\
\hline Urethral striated muscle area/total area & $0.37 \pm 0.05^{\mathbf{A}}$ & $0.33 \pm 0.04^{\mathrm{AB}}$ & $0.31 \pm 0.06^{\mathbf{A B}}$ & $0.28 \pm 0.08^{\mathbf{B}}$ \\
\hline Urethral connective tissue area/total area & $0.33 \pm 0.08^{\mathrm{A}}$ & $0.33 \pm 0.05^{\mathrm{A}}$ & $0.34 \pm 0.12^{\mathrm{A}}$ & $0.39 \pm 0.11^{\mathrm{A}}$ \\
\hline Urethral connective tissue in striated area/striated muscle area & $0.48 \pm 0.17^{\mathbf{A B}}$ & $0.40 \pm 0.07^{\mathrm{A}}$ & $0.49 \pm 0.17^{\mathbf{A B}}$ & $0.71 \pm 0.37^{\mathbf{B}}$ \\
\hline Urethral connective tissue in smooth area/smooth muscle area & $0.70 \pm 0.26^{\mathbf{A}}$ & $0.76 \pm 0.18^{\mathrm{A}}$ & $0.89 \pm 0.30^{\mathrm{A}}$ & $0.65 \pm 0.25^{\mathrm{A}}$ \\
\hline Urethral connective tissue in striated area/urethral connective tissue in smooth area & $1.50 \pm 0.40^{\mathbf{A B}}$ & $0.94 \pm 0.31^{\mathrm{A}}$ & $1.10 \pm 0.42^{\mathrm{AB}}$ & $1.65 \pm 0.82^{\mathbf{B}}$ \\
\hline
\end{tabular}

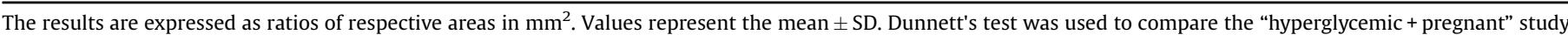

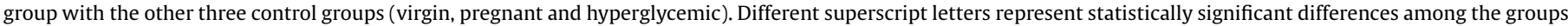
with $\mathrm{p} \leq 0.05$. 
Virgin

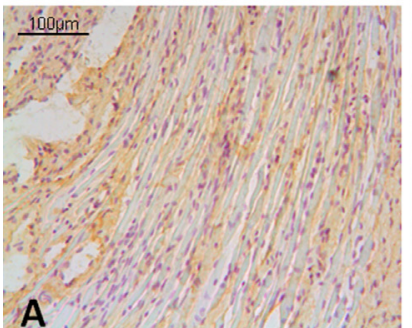

Hyperglycemic

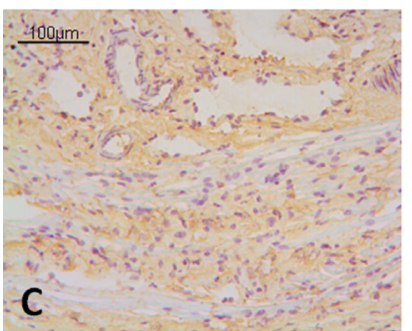

Virgin

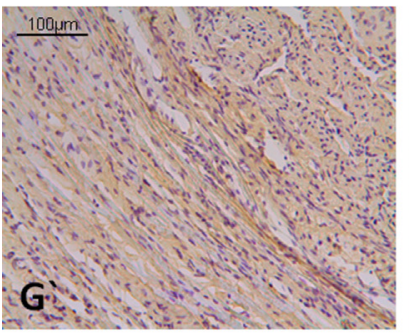

Hyperglycemic

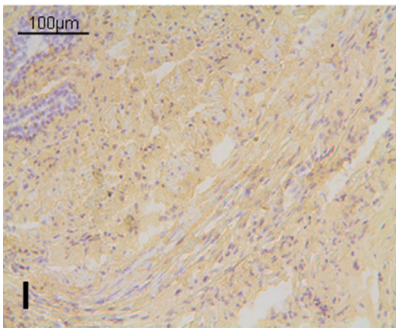

Pregnant

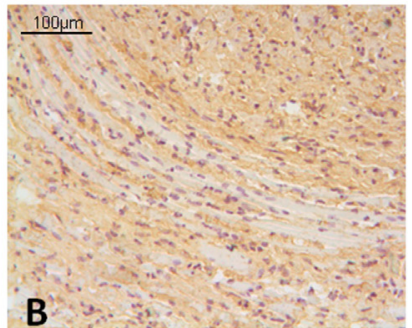

Hyperglycemict Pregnant

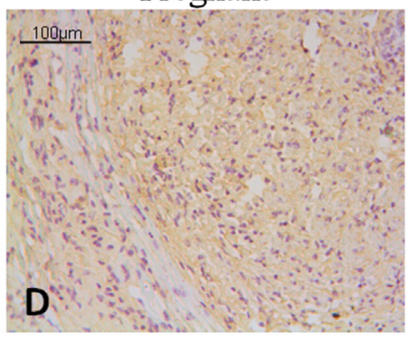

Pregnant

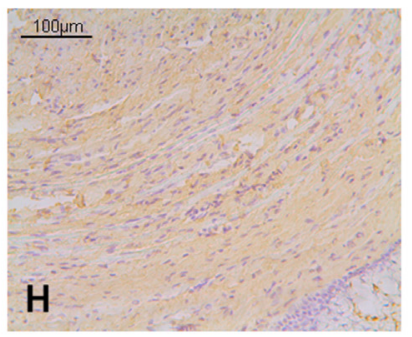

Hyperglycemic+ Pregnant

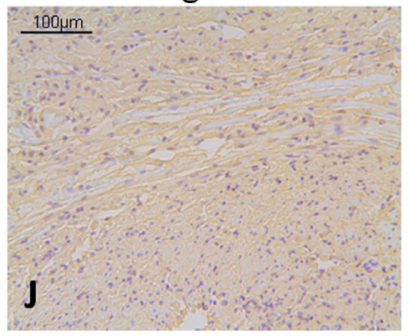

$\mathbf{E}$

Collagen I

$\beta$-Actin

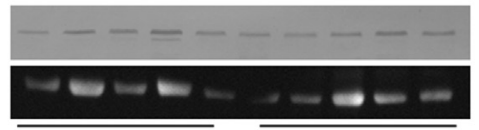

$130 \mathrm{kDa}$

$42 \mathrm{kDa}$

Collagen I

$\beta$-Actin

$\begin{array}{llllllllll}11 & 12 & 13 & 14 & 15 & 16 & 17 & 18 & 19 & 20\end{array}$

$130 \mathrm{kDa}$

$42 \mathrm{kDa}$

\section{$\mathbf{F}$}

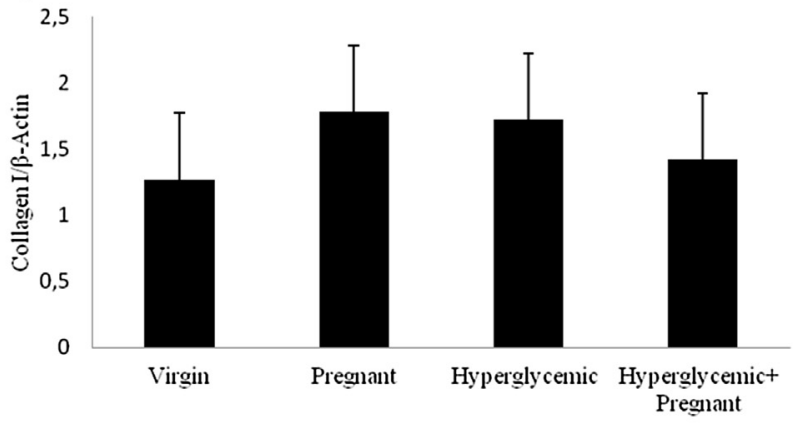

K
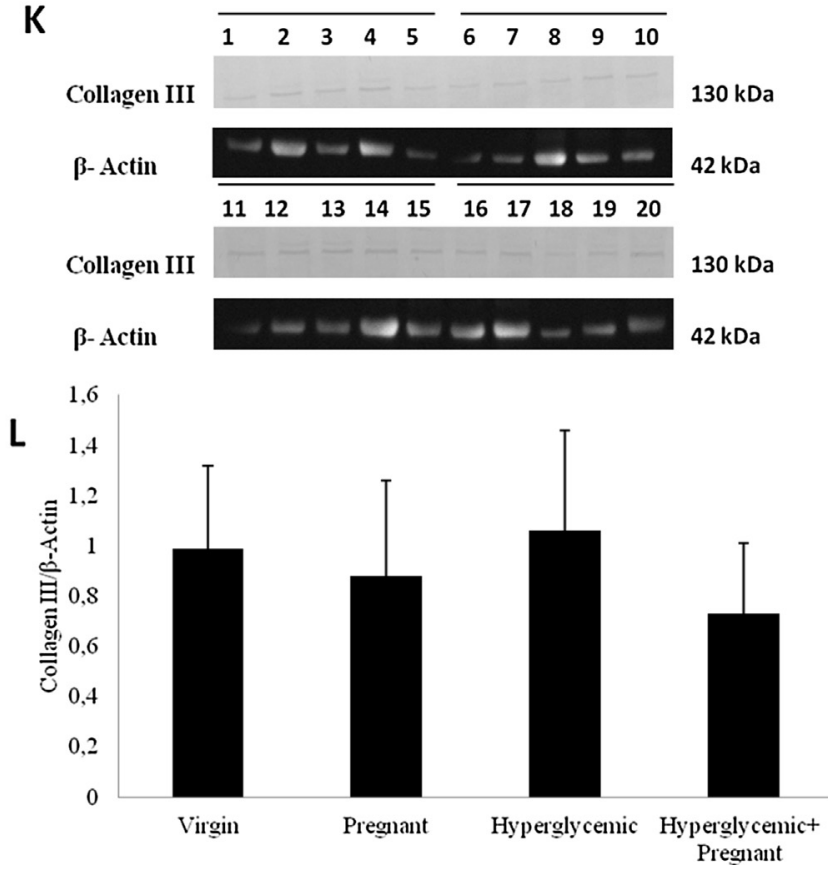

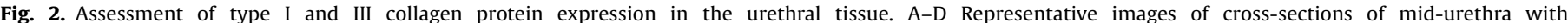

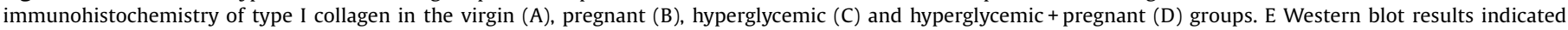

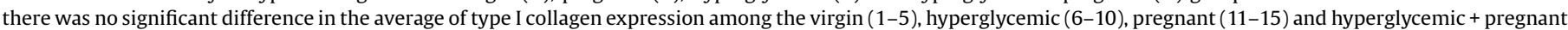

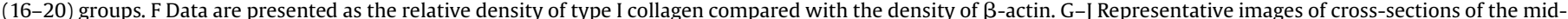

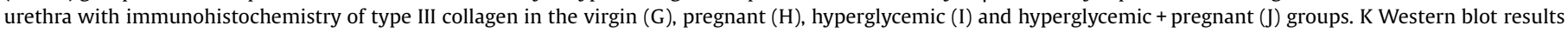

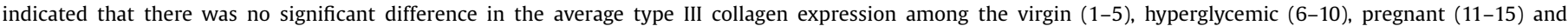

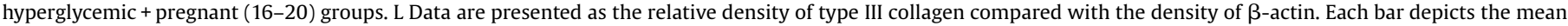
value \pm SD

This change observed in the organization of the collagen fibrils was also seen by Falconer et al. in paraurethral connective tissue in women of fertile age with stress urinary incontinence, suggesting a more rigid form of extracellular matrix, resulting in connective tissue with impaired mechanical function [25].

The increased collagen type I/III ratio confirmed the importance of utilizing a biological approach to understand the pathogenesis of PFD in diabetic patients. Changes to the amount and distribution of different types of collagen can influence the biomechanical properties of the bladder and urethra. It has been suggested that the collagen type I/III ratio is an important factor related to bladder and urethral dysfunction [26]. Our findings suggest the presence of a more rigid structure, supportive collagen around the urethra, favors stiffer urethral tissue, which can impair the biomechanical properties of the tissue and complicate urethra closure and urinary continence [27]. All these changes have the potential to cause significant urinary tract injury, as has been observed in radiationinduced injury of the urinary tract [28]. 


\section{Collagen Type I/III ratio}

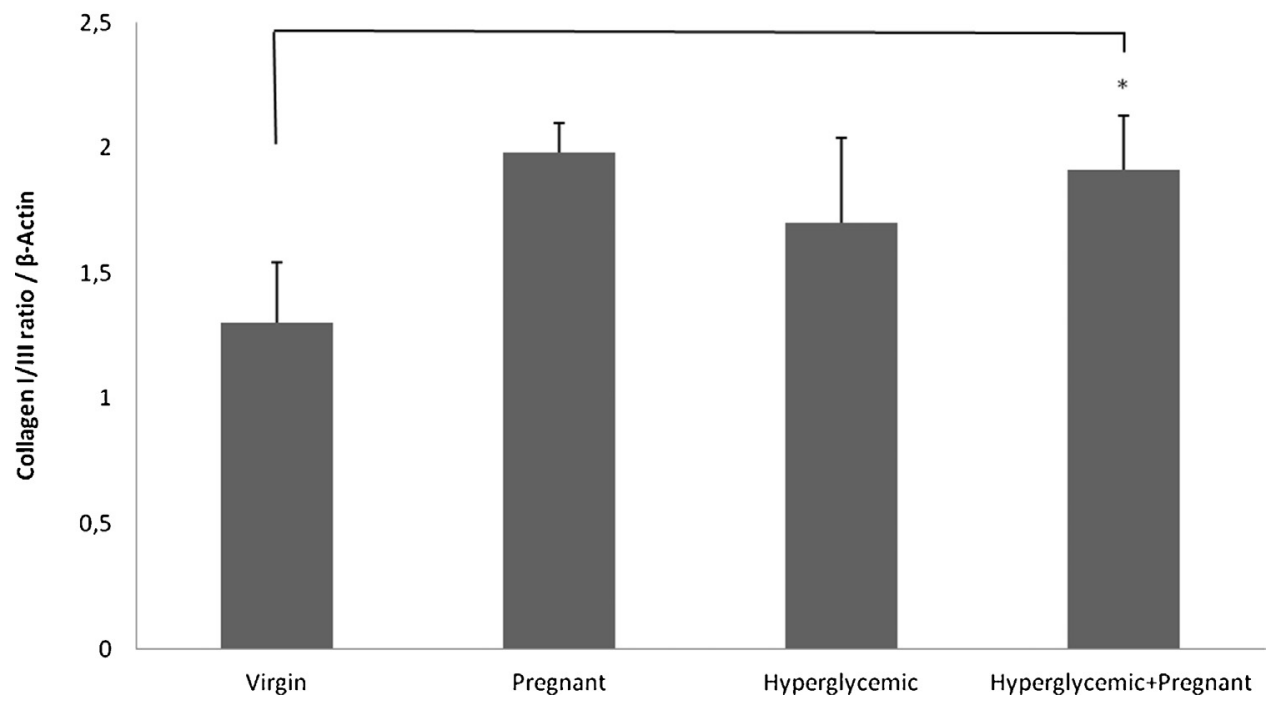

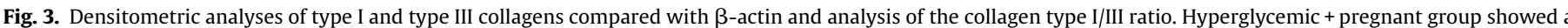

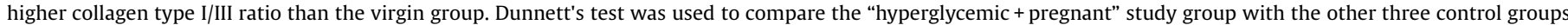
(virgin, pregnant and hyperglycemic). Different superscript letters represent statistically significant differences among the groups with $\mathrm{p} \leq 0.05$.

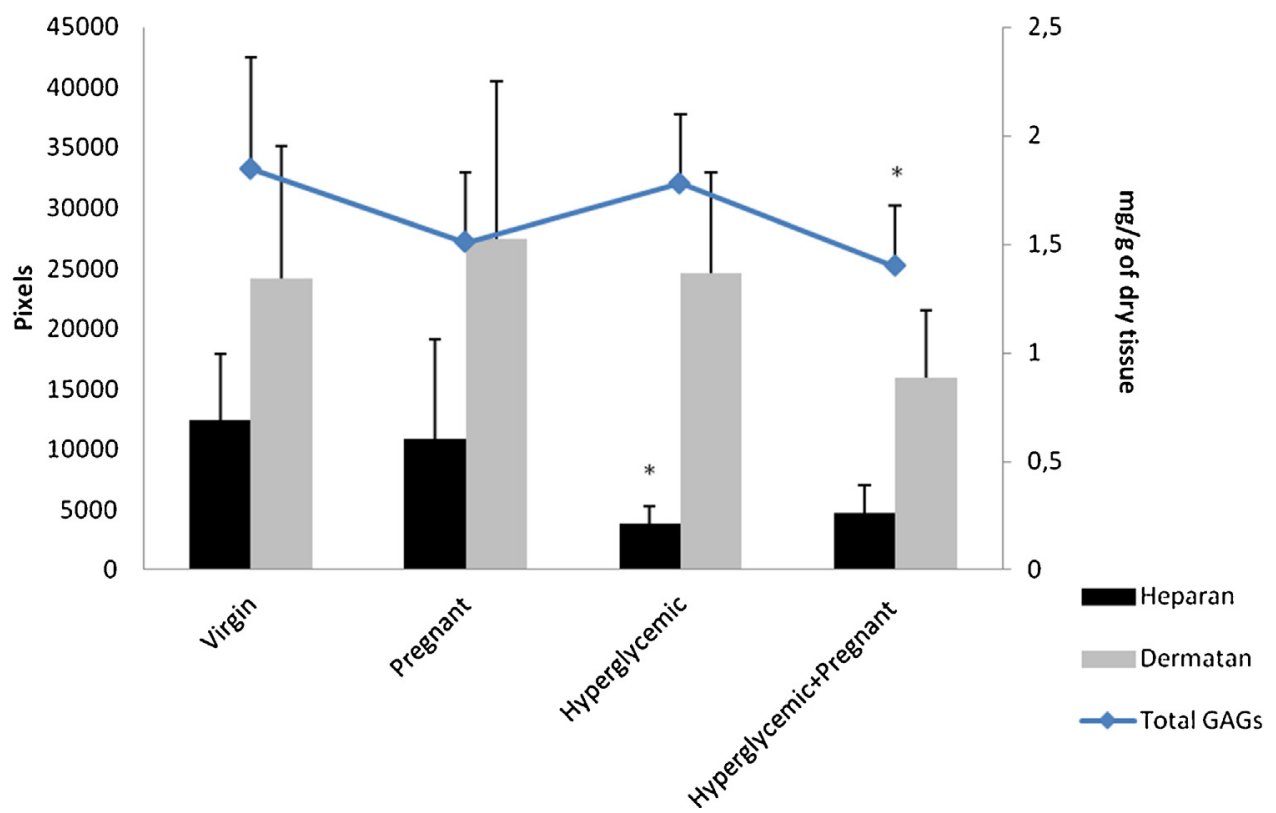

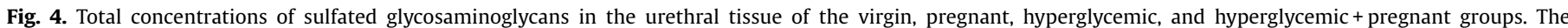

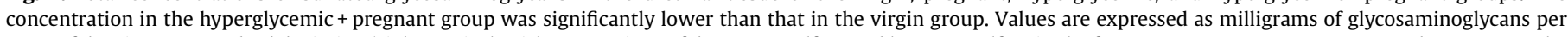

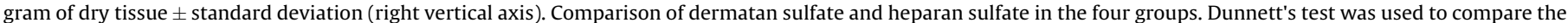

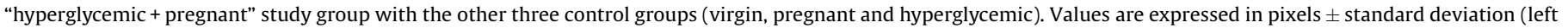
vertical axis).

Gharaee-Kermani et al. (2013) suggested that obesity, DM, lower urinary tract fibrosis and urinary voiding dysfunction are inextricably and biologically linked [29]. Diabetes-associated alterations in collagen (tissue stiffness) have been described in human studies of vascular stiffness [30] and skeletal muscles [31], in various animals studies of the urethra [26,32], and in studies of the urinary bladder in rats [33,34].

Research into GAGs is still in an early stage. The increase in reactive oxygen species (ROS) as a result of hyperglycemia may lead to modifications of GAGs. Because of their negative charge, GAGs can attract components of oxidant systems, thus encouraging the formation of ROS. All GAGs have the potential to be damaged by oxidant systems. Inflammation, commonly associated with diabetes, may contribute to the destruction and modification of GAGs [35]. To the best of our knowledge, there are still no data on GAG composition in urethral tissue in a severe STZ-induced diabetic pregnant rat model.

In addition, elevated glucose levels impair collagen production and intensify the presence of AGEs, resulting in stiffening of collagen tissues [36]. The primary mechanical effect of AGEs is a loss of tissue viscoelasticity driven by matrix-level loss of fiberfiber sliding with potentially important implications in tissue 
damage accumulation, mechanically regulated cell signaling, and matrix remodeling [37].

Extracellular matrix proteins are susceptible to AGE modification because of their slow turnover rate. The formation of intermolecular and intramolecular crosslinks with collagen (as a result of the glycation process) leads to structural alterations, increased stiffness and resistance to proteolytic digestion [38]. ECM remodeling in insulin-resistant skeletal muscle is of potential significance for muscle metabolism, and increased levels of type I and III collagens are found in skeletal muscle biopsies in patients with type 2 diabetes [31]. In addition, patients with recurrent prolapse and joint hypermobility have significantly high concentrations of type III procollagen [39]. Furthermore, diabetes can induce increased fibrosis in the bladders of rats, likely due to the dysregulation of type 1 matrix metalloproteinases (MMPs) and type 1 endogenous tissue inhibitors of metalloproteinases (TIMPs) [34].

\section{Conclusions}

This translational study provides the first line of experimental evidence supporting a metabolic relationship between hyperglycemia and remodeling of urethral connective tissue in pregnant rats. The different organization of collagen fibrils and the profile of GAGs found in urethral samples suggest that pathology of the urethral fibromuscular system could be related to hyperglycemiainduced pelvic floor dysfunction in women. To further address these questions, large cohort studies are required, including analyses of the collagen type I/III ratio, to identify diabetic pregnant women at high risk of PFD. Therefore, the processes leading to urethral remodeling can be considered for future studies of new therapeutic targets.

\section{Conflict of interest}

The authors declare that they have no conflict of interest.

\section{Funding}

This work was supported by grant \#2010/11703-4 and 2010/ 10740-3, São Paulo Research Foundation (FAPESP)/Brazil.

\section{Author contributions}

Gabriela MARINI: conception and design, acquisition of data, analysis and interpretation of data, manuscript writing; Fernanda PICULO: acquisition of data and interpretation of data; Giovana VESENTINI: acquisition of data and interpretation of data; Débora C. DAMASCENO: conception and design, analysis and interpretation of data, manuscript writing; Flávia K. DELELLA: analysis and interpretation of data, manuscript writing; Iracema M. P. CALDERON: analysis and interpretation of data; Firouz DANESHGARI: analysis and interpretation of data, manuscript writing; Sérgio L. FELISBINO: conception and design, analysis and interpretation of data, manuscript writing; Angélica M. P. BARBOSA: interpretation of data, manuscript writing; Marilza V. C. RUDGE: conception and design, analysis and interpretation of data, manuscript writing.

\section{Acknowledgements}

The authors thank the staff of the Laboratory for Experimental Research in Gynecology and Obstetrics, Laboratory of Anatomy and Morphology and Department of Structural and Functional Biology in State University of Campinas, especially to Talísia Moretto and Gelson Rodrigues. They also thank Andrea A. Aro (Institute of Biology, State University of Campinas, UNICAMP, Campinas-SP,
Brazil) for the excellent technical and scientific contributions to the GAG analysis.

\section{References}

[1] Guariguata L, Whiting DR, Hambleton I, Beagley J, Linnenkamp U, Shaw JE. Global estimates of diabetes prevalence for 2013 and projections for 2035. Diabetes Res Clin Pract 2014;103(2):137-49.

[2] Wu JM, Vaughan CP, Goode PS, Redden DT, Burgio KL, Richter HE, et al. Prevalence and trends of symptomatic pelvic floor disorders in U.S. women. Obstet Gynecol 2014;123(1):141-8.

[3] Lenherr SM, Clemens JQ, Braffett BH, Dunn RL, Cleary PA, Kim C, et al. Glycaemic control and risk of incident urinary incontinence in women with type 1 diabetes: results from the diabetes control and complications trial and epidemiology of diabetes interventions and complications (DCCT/EDIC) study. Diabet Med 2016;33(11):1528-35.

[4] Sangsawang B. Risk factors for the development of stress urinary incontinence during pregnancy in primigravidae: a review of the literature. Eur J Obstet Gynecol Reprod Biol 2014;178:27-34.

[5] Jimenez-Rodriguez J, Carbajal-Ramirez A, Meza-Vazquez H, Moreno-Palacios J, Serrano-Brambila E. Prevalence of urinary tract symptoms in women with diabetes mellitus. Rev Med Inst Mex Seguro Soc 2016;54(1):70-4.

[6] Wang R, Lefevre R, Hacker MR, Golen TH. Diabetes, glycemic control, and urinary incontinence in women. Female Pelvic Med Reconstr Surg 2015;21 (5):293-7.

[7] Isik H, Aynioglu O, Sahbaz A, Selimoglu R, Timur H, Harma M. Are hypertension and diabetes mellitus risk factors for pelvic organ prolapse? Eur J Obstet Gynecol Reprod Biol 2016;197:59-62.

[8] Barbosa AM, Dias A, Marini G, Calderon IM, Witkin S, Rudge MV. Urinary incontinence and vaginal squeeze pressure two years post-cesarean delivery in primiparous women with previous gestational diabetes mellitus. Clinics 2011;66(8):1341-6.

[9] Chuang CM, Lin IF, Horng HC, Hsiao YH, Shyu IL, Chou P. The impact of gestational diabetes mellitus on postpartum urinary incontinence: a longitudinal cohort study on singleton pregnancies. BJOG 2012;119 (11):1334-43.

[10] Morgan DM, Umek W, Guire K, Morgan HK, Garabrant A, DeLancey JO. Urethral sphincter morphology and function with and without stress incontinence. J Urol 2009;182(1):203-9.

[11] DeLancey JO, Trowbridge ER, Miller JM, Morgan DM, Guire K, Fenner DE, et al. Stress urinary incontinence: relative importance of urethral support and urethral closure pressure. J Urol 2008;179(6):2286-90.

[12] Fitzgerald MP, Mollenhauer J, Hale DS, Benson JT, Brubaker L. Urethral collagen morphologic characteristics among women with genuine stress incontinence. Am J Obstet Gynecol 2000;182(6):1565-74.

[13] Feldner Jr. PC, Sartori MG, Nader HB, Dietrich CP, Rodrigues de Lima G, Baracat EC, et al. Sulfated glycosaminoglycans of periurethral tissue in pre- and postmenopausal women. Eur J Obstet Gynecol Reprod Biol 2008;139(2):2525.

[14] Eckes B, Zigrino P, Kessler D, Holtkotter O, Shephard P, Mauch C, et al. Fibroblast-matrix interactions in wound healing and fibrosis. Matrix Biol 2000;19(4):325-32.

[15] Liapis A, Bakas P, Pafiti A, Frangos-Plemenos M, Arnoyannaki N, Creatsas G. Changes of collagen type III in female patients with genuine stress incontinence and pelvic floor prolapse. Eur J Obstet Gynecol Reprod Biol 2001;97(1):76-9.

[16] Feldner Jr. PC, Kati LM, Sartori MG, Baracat EC, Rodrigues de Lima G, Nader HB, et al. Sulfated glycosaminoglycans of the periurethral tissue in women with and without stress urinary incontinence, according to genital prolapse stage. Eur J Obstet Gynecol Reprod Biol 2006;126(2):250-4.

[17] Chen HY, Lin YN, Chen YH, Chen WC. Stress urinary incontinence following vaginal trauma involves remodeling of urethral connective tissue in female mice. Eur J Obstet Gynecol Reprod Biol 2012;163(2):224-9.

[18] Duran-Jimenez B, Dobler D, Moffatt S, Rabbani N, Streuli CH, Thornalley PJ, et al. Advanced glycation end products in extracellular matrix proteins contribute to the failure of sensory nerve regeneration in diabetes. Diabetes 2009;58(12):2893-903.

[19] Campeau L, Gorbachinsky I, Badlani GH, Andersson KE. Pelvic floor disorders: linking genetic risk factors to biochemical changes. BJU Int 2011;108(8):12407.

[20] Alperin M, Kaddis T, Pichika R, Esparza MC, Lieber RL. Pregnancy-induced adaptations in intramuscular extracellular matrix of rat pelvic floor muscles. Am J Obstet Gynecol 2016215(2) 210 e1-7.

[21] Zhang X, Alwaal A, Lin G, Li H, Zaid UZ, Wang G, et al. Urethral musculature and innervation in the female rat. Neurourol Urodyn 2016;35(3):382-9.

[22] Marini G, Barbosa AM, Damasceno D, Matheus SMM, Castro RA, Girão MJBC, et al. Morphological changes in the fast vs slow fiber profiles of the urethras of diabetic pregnant rats. Urogynaecologia 201125: e9:31-6.

[23] Piculo F, Marini G, Barbosa AM, Damasceno DC, Matheus SM, Felisbino SL, et al. Urethral striated muscle and extracellular matrix morphological characteristics among mildly diabetic pregnant rats: translational approach. Int Urogynecol J 2014;25(3):403-15.

[24] Marini G, Piculo F, Vesentini G, Barbosa AM, Damasceno DC, Matheus SM, et al. Effects of short-term severe and long-term mild STZ-induced diabetes in urethral tissue of female rats. Neurourol Urodyn 2016;36(3):574-9. 
[25] Falconer C, Blomgren B, Johansson O, Ulmsten U, Malmstrom A, WestergrenThorsson G, et al. Different organization of collagen fibrils in stressincontinent women of fertile age. Acta Obstet Gynecol Scand 1998;77 (1):87-94.

[26] Rodrigues Jr. AA, Suaid HJ, Fazan VP, Reis RB, Cologna AJ, Tucci Jr. S, et al. Histologic study of urethral extracellular matrix and collagen from aging and long-term alloxan-induced diabetic male rats. Urology 201177(2) 510 e6-11.

[27] Tibbs MK. Wound healing following radiation therapy: a review. Radiother Oncol 1997;42(2):99-106.

[28] Liberman D, Mehus B, Elliott SP. Urinary adverse effects of pelvic radiotherapy. Transl Androl Urol 2014;3(2):186-95.

[29] Gharaee-Kermani M, Rodriguez-Nieves JA, Mehra R, Vezina CA, Sarma AV, Macoska JA. Obesity-induced diabetes and lower urinary tract fibrosis promote urinary voiding dysfunction in a mouse model. Prostate 2013;73 (10):1123-33.

[30] Jia G, Aroor AR, DeMarco VG, Martinez-Lemus LA, Meininger GA, Sowers JR. Vascular stiffness in insulin resistance and obesity. Front Physiol 2015;6:231.

[31] Berria R, Wang L, Richardson DK, Finlayson J, Belfort R, Pratipanawatr T, et al. Increased collagen content in insulin-resistant skeletal muscle. Am J Physiol Endocrinol Metab 2006;290(3):E560-5.
[32] Kim JH, Huang X, Liu G, Moore C, Bena J, Damaser MS, et al. Diabetes slows the recovery from urinary incontinence due to simulated childbirth in female rats. Am J Physiol Regul Integr Comp Physiol 2007;293(2):R950-5.

[33] Wu L, Zhang X, Xiao N, Huang Y, Kavran M, Elrashidy RA, et al. Functional and morphological alterations of the urinary bladder in type 2 diabetic $\mathrm{FVB}(\mathrm{db} / \mathrm{db})$ mice. J Diabetes Complicat 2016;30(5):778-85.

[34] Elrashidy R, Xu Z, Daneshgari G, Liu G. MP 31-14 imbalance between matrix etalloproteinase-1 (MMP-1) and tissue inhibitor of metalloproteinase-1 (TIMP-1) contributes to increased fibrosis of bladder in long-term diabetic rats. J Urol 2017;197(4):e404.

[35] Hiebert LM, Han J, Mandal AK. Glycosaminoglycans, hyperglycemia, and disease. Antioxid Redox Signal 2014;21(7):1032-43.

[36] Gautieri A, Redaelli A, Buehler MJ, Vesentini S. Age- and diabetes-related nonenzymatic crosslinks in collagen fibrils: candidate amino acids involved in advanced glycation end-products. Matrix Biol 2014;34:89-95.

[37] Li Y, Fessel G, Georgiadis M, Snedeker JG. Advanced glycation end-products diminish tendon collagen fiber sliding. Matrix Biol 2013;32(3-4):169-77.

[38] Kolset SO, Reinholt FP, Jenssen T. Diabetic nephropathy and extracellular matrix. J Histochem Cytochem 2012;60(12):976-86.

[39] Knuuti E, Kauppila S, Kotila V, Risteli J, Nissi R. Genitourinary prolapse and joint hypermobility are associated with altered type I and III collagen metabolism. Arch Gynecol Obstet 2011;283(5):1081-5. 